\title{
COLORINDO OS CHAPÉUS: UMA EXPERIÊNCIA DE FORMAÇÃO DE LEITORES- CONTADORES MIRINS
}

\section{COLORING HATS: AN EXPERIMENT IN THE EDUCATION OF CHILDREN AS STORY TELLERS}

\section{RESUMO}

O presente texto relata algumas reflexões e ações realizadas em etapas de dois projetos de extensão, "Rodas de leitura: um caminho para formar leitores" e "Contar histórias: um trabalho de sala de aula", em desenvolvimento na Universidade Federal do Tocantins, Câmpus de Arraias. Dentre as ações desenvolvidas, apresentamos aqui um trabalho realizado com a obra de literatura infantil "Chapeuzinhos Coloridos", de José Roberto Torero e Marcus Aurelius Pimenta, em duas instituições de ensino do município de Arraias - TO. O trabalho originou-se dos desdobramentos das atividades extensionistas nas escolas quando do encanto de alunos e professores no momento do compartilhamento "em roda" da referida obra, ilustrando aos professores da escola, participantes do projeto, como e por que contar histórias e montar rodas de leituras em sala. A experiência reforçou a convicção anterior da importância de formações iniciais e continuadas, bem como da troca de experiências para a constituição da identidade docente.

Palavras-chave: chapeuzinhos coloridos; contação de histórias; rodas de leitura; formação; leitores.

\section{ABSTRACT}

The present text reports some reflections and actions carried out in different phases of two extension projects, "Reading circles: a way to train readers" and "Storytelling: a classroom work", under development at the Federal University of Tocantins, in Arraias Campus. Among the actions developed, we present here a work done with the children's literature "Chapeuzinhos Coloridos" ("Colorful Hats"), by José Roberto Torero and Marcus Aurelius Pimenta, in two educational institutions of the municipality of Arraias - TO. The work

*Professora da Universidade Federal do Tocantins (UFT), TO - Brasil. E-mail: astephani@uft.edu.br 
originated from the unfolding of extension activities in schools in which the enchantment of students and teachers at the moment of sharing the text "in circles", showed the teachers of the school, participants of the project, how and why to tell stories and to organize reading circles in the classroom. The experience reinforced the previous conviction of the importance of initial and continuing training, as well as of the exchange of experiences for the constitution of the teaching identity.

Keywords: chapeuzinhos coloridos (colorful hats); story telling; reading circles; education; readers.

\section{Consideraçóes iniciais}

Desde o ano de 2010, açóes de pesquisa e extensão estão sendo desenvolvidas vinculadas ao curso de Pedagogia da Universidade Federal do Tocantins (UFT), Câmpus de Arraias. Algumas delas investigam a realidade e o perfil dos leitores e escritores da Educaçáo Básica da região e da universidade, bem como propóem alternativas de trabalho para o desenvolvimento de competências e habilidades de leitura e escrita.

No que tange à pesquisa, podemos citar o projeto de pesquisa "A Leitura e a produção textual na graduação: o real e o ideal", que analisa o perfil de leitura e escrita dos universitários, para, em seguida, serem propostas açóes para dirimir as lacunas nas práticas existentes dos alunos nessas áreas.

O projeto discute a importância da formaçáo dos futuros professores (e dos já em exercício na Educação Básica) enquanto leitores e escritores, e a discussáo embasa outras pesquisas e açóes de extensão, a exemplo as duas apresentadas neste texto: "Rodas de leitura: um caminho para formar leitores" e "Contar histórias: um trabalho de sala de aula". O objetivo é discutir e proporcionar a aquisição da teoria da leitura literária, inclusive nos aspectos da recepção dos textos, bem como o aumento do repertório literário desses (futuros) profissionais para que o processo de mediação de leitura em sala de aula realmente se efetive.

O projeto de extensão "Rodas de leitura: um caminho para formar leitores" iniciou-se em 2015 e se estrutura em três etapas, assim descritas, mas não necessariamente em sequência: estudos teóricos sobre leitura e formação do leitor (CANDIDO, 1979; ZILBERMAN, 1988; COSSON, 2006); conceitos sobre rodas de leitura e mediação (SANTOS; ROSING, 2009; SILVA, 2009; GERALDI, 2013; COSSON, 2014); e, desenvolvimento de rodas de leitura com os participantes (VARGAS, 1997; DANIELS, 2002). O Projeto visa não somente preparar profissionais para a organização de rodas de leitura, mas também desenvolvê-las em diferentes espaços, inclusive na Universidade.

O projeto "Contar histórias: um trabalho de sala de aula" objetiva ofertar cursos de capacitação para os alunos do curso de Pedagogia da UFT - Câmpus de Arraias e os professores das redes municipais e estaduais de ensino na arte de contar histórias e como melhor desenvolvê-la nas escolas e creches da região. Além da ação de formação docente, há momentos de contação de histórias nas escolas e em diferentes ambientes. Para embasarmos nosso trabalho, utilizamos os fundamentos teóricos metodológicos e literários dos autores: Abramovich (1988), Aguiar e Bordini (1988); Bettelheim (1980); Busatto (2003); Machado (2002); Machado (2004); Mellon (2009); Coelho (1997), dentre outros.

Diversas escolas participaram indiretamente dos projetos em epígrafe, via desenvolvimento das ações por parte dos participantes dos cursos. No entanto, em duas delas pudemos desenvolver açóes mais pontuais: o Centro Municipal de Educação Básica (CMEB) Professora Lívia Lorene Bueno Maia e a Cooperativa Educacional de Pais de Arraias (CEPAR). Em parceria com 2 (duas) professoras regentes,

1 Os dois projetos são apoiados pelo PRODOCÊNCIA, um modelo de programa que visa ampliar a qualidade das ações voltadas à formação de professores, com prioridade para a formação inicial desenvolvida nos cursos de licenciaturas das instituições federais e estaduais de educação superior, dando suporte financeiro para a reestruturação dos laboratórios e a implementação de ações de práticas de ensino. 
sendo uma de cada escola, desenvolvemos açóes de contaçáo de histórias e de rodas de leitura.

Assim, no presente relato, apresentamos algumas ações e reflexóes realizadas nesses momentos, envolvendo a obra de literatura infantil "Chapeuzinhos Coloridos", de José Roberto Torero e Marcus Aurelius Pimenta, uma releitura do clássico "Chapeuzinho Vermelho", ação que, além de ilustrar aos professores métodos de contação e mediação de histórias, resultou na formação de leitores/contadores mirins. E para dar início a essa discussão, apresentamos um pouco da vertente teórica que orienta nosso trabalho e reflexões.

\section{Formando leitores de literatura em espaços escolares}

"A leitura de mundo precede a leitura da palavra" lembra Freire (1992, p. 11), em suas discussóes sobre a formaçáo de leitores de mundo e para o mundo. E quando esse processo de formaçáo de um leitor se inicia? Inúmeros autores e pesquisas apontam que ler é um ato que se inicia tão logo o indivíduo tenha compreensão do que está à sua volta e desenvolve-se paulatinamente nas relaçóes sociais e com o mundo.

Assim, tudo o que se ouve e se vê amplia a capacidade leitora de um ser e isso ocorre muito antes de se aprender a decodificar a leitura a partir do texto escrito. Deste modo, "o ato de ler se refere tanto a algo escrito quanto a outros tipos de expressão do fazer humano, caracterizando-se também como acontecimento histórico e estabelecendo uma relação igualmente histórica entre o leitor e o que é lido" (MARTINS, 1985, p. 30).

Diversos autores defendem e discutem a importância de trabalhar a literatura com crianças desde a mais tenra idade e apresentam todos os benefícios que esse trabalho pode proporcionar. Dentre eles, destacam-se: Abramovich (1988), Aguiar e Bordini (1988), Bettelheim (1980), Busatto (2003), Donatto (2005), Machado (2002), Machado (2004), Mellon (2009) e Coelho (1997). Para esses autores, o ato de contar histórias trabalhado com a literatura de uma aconchegante e atraente - possibilita a quem ouve, principalmente às crianças, um processo de formação pessoal e social.

Levando isso em consideração, podemos dizer que o lido/ouvido na infância alicerça a formação do leitor e do cidadão, pois as relaçóes estabelecidas nesse contato propiciam internalizaçóes e reflexóes: a existência do bem e do mal, de bruxas e fadas, das dificuldades da vida e dos finais felizes possíveis.

Segundo Coelho (1997), é nesse processo de amadurecimento interior que a literatura infantil e, principalmente, os contos de fadas podem ser decisivos para a formação da criança em relação a si mesma e ao mundo a sua volta. De acordo com a autora, "a força da história é tamanha que narrador e ouvintes caminham juntos na trilha do enredo e ocorre uma vibraçáo recíproca de sensibilidades, a ponto de diluir-se o ambiente real ante a magia da palavra que comove e enleva” (COELHO, 1997, p. 11).

Além desses aspectos, uma criança que tem contato com diversas histórias e tem uma relaçáo de proximidade com a literatura possui maiores chances de ser um bom leitor, o que propicia sua formação enquanto escritor. A falta desse contato constante com o texto literário desde a infância deixa lacunas que nem sempre seráo corrigidas nos anos escolares seguintes, o que implica na atual realidade da leitura no país. Isso porque, 
[a] literatura desempenha entre outras funçôes, como a de evasão e a de diversão, a função de transmitir conhecimento, e a principal função de contribuir de forma única na humanização do homem. A literatura é arte, e como tal faz parte da cultura. E é mais, porque dentre todos os tipos de arte é nela que encontramos o maior repertório de conhecimento que a humanidade já produziu (DONATTO, 2005, p. 16).

Em vista disso, contar e compartilhar histórias faz-se oportuno e necessário nos espaços escolares e não escolares, trazendo aos pequenos o desvelar do mundo. No entanto, a maioria das crianças têm contato com histórias contadas e/ou compartilhadas apenas na escola. Entáo, o que muitos alunos têm a esse respeito é dado pelos professores. Porém, muitos professores não têm a devida instrução nem a oportunidade de desenvolver as competências e habilidades para esse trabalho e é isso que os projetos de extensão desenvolvidos junto a Universidade Federal do Tocantins visam.

\section{"Chapeuzinho": Leituras e releituras que encantam crianças de todas as geraçóes}

"Chapeuzinho Vermelho" é uma narrativa clássica da literatura infantil mundial, traduzida para centenas de línguas, lida e contada/transmitida por milhóes de adultos e crianças. Sua origem não pode ser datada, pois se configura como conto popular emanado da oralidade.

O antropólogo Tehrani (2013), em uma análise filogenética da historinha de "Chapeuzinho Vermelho", relacionando-a com outras histórias, aponta, por exemplo, que variaçóes das personagens de Chapeuzinho, do Lobo e da Vovó aparecem em contos europeus, asiáticos e africanos, possuindo registros e elementos próprios, de acordo com cada cultura.

A história de título homônimo ao personagem principal foi escrita (compilada da oralidade) primeiramente pelo escritor francês Charles Perrault, no século XVII (1697), ${ }^{2}$ e foi largamente propalada no século XIX, pelos alemães Irmãos Grimm (DARNTON, 1996).

Dificilmente se encontra alguém que não conheça pelo menos uma versáo dessa narrativa. A mais popular (uma adaptaçáo da primeira narrativa a ser registrada) e comumente encontrada e contada por muitas crianças é a de uma menina de capuz vermelho, que é devorada por um lobo ao levar doces para sua avó materna, que, assim como ela, é salva por um caçador, que consegue que sejam "desengolidas", seja por meio do corte da barriga do lobo ou por outras peripécias criadas pelos seus diferentes "recontadores".

De base oral, a narrativa ganhou inúmeras versóes, nas quais há uma variedade de elementos que são inseridos/transformados, chegando até à própria mudança da cor do capuz da menina.

No Brasil, encontram-se diversos autores nacionais que se debruçaram nesse trabalho, entre os quais destacam-se: Rosa (1992), com o conto "Fita-verde no cabelo: nova velha história", publicado pela primeira vez em 1964; Prata (1970), com "Chapeuzinho Vermelho de raiva"; Buarque (2012), com "Chapeuzinho Amarelo" (primeira edição em

2 A narrativa faz parte de uma coletânea (Contos de Mamãe Gansa) de contos do folclore popular de seu país, organizada por Charles Perrault, transformados em histórias para criança. 
1979); e, recentemente, os autores Torero e Pimenta (2010), com seus "Chapeuzinhos Coloridos".

Dentre essas obras, aprofundamo-nos na última, objeto do presente trabalho em rodas de leitura e em momentos de contaçáo de histórias. Assim como os demais autores, Torero e Pimenta (2010) partem de uma estrutura central da narrativa clássica e reconduzem o desenrolar dos fatos, seguindo uma linha temática.

Para começar, os chapeuzinhos não são vermelhos. São azul, verde, branco, lilás, cor de abóbora e preto. $\mathrm{E}$ as histórias também são diferentes. Tem uma em que a Chapeuzinho é malvada, outra em que ela quer ser famosa, uma em que a Chapeuzinho é gordinha, outra em que ela quer ganhar dinheiro, uma sobre amizade e outra sobre o tempo. (TORERO; PIMENTA 2010, p. 5).

Diversos temas são abordados nas narrativas de "Chapeuzinhos Coloridos", e muitos dos quais associam a cor da personagem principal a sentimentos e valores: animais em extinção (azul), alimentação/gula (abóbora), dinheiro/ganância (verde), solidão (branco), fama (lilás), tempo/morte (preto).

A capa da obra traz as seis personagens das seis releituras, com seus capuzes coloridos (azul, verde, branco, lilás, cor de abóbora e preto). Na apresentação da coletânea de histórias, os autores já apontam o caminho que optaram para seguir nos recontos. Eles também sugerem aos leitores que igualmente criem novas "Chapeuzinhos" e até sugerem outras histórias que poderiam ser escritas.

Nas imagens a seguir, podemos observar detalhes gráficos da obra:

Figura 1: Capa e partes da obra Chapeuzinhos Coloridos
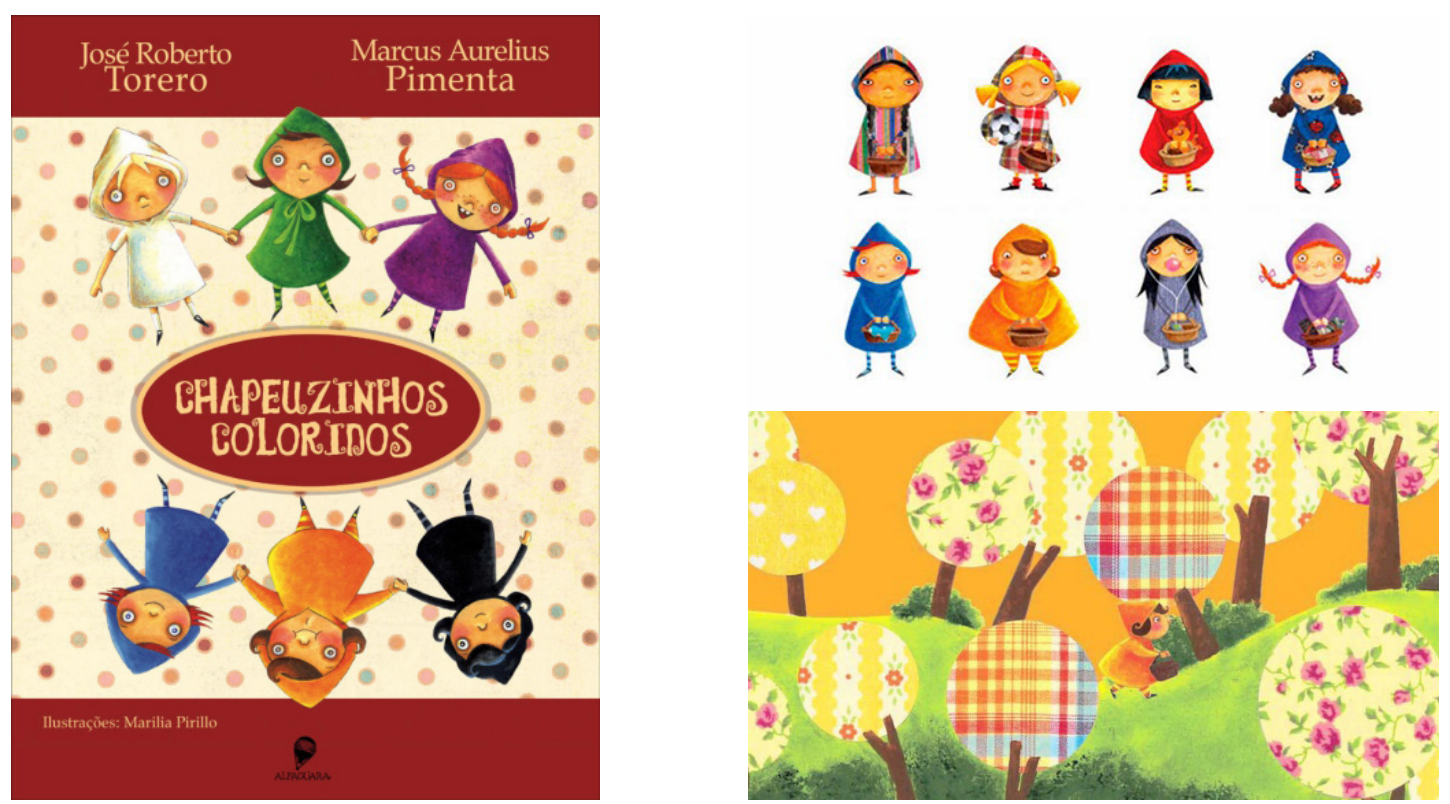

O enredo de cada narrativa gira em torno de uma menina de capuz que leva uma encomenda de sua mãe para a casa de sua vó e, no caminho, encontra com um lobo, que a questiona sobre seu trajeto, sugerindo outro. Quanto aos desfechos, são todos inusitados: o lobo é assado pela vovozinha, é adotado, é morto pelo caçador, explode, representa o tempo/morte, e se vai. 
Além da tentativa de relação entre cores e sentimentos e valores, a descrição da personagem principal, a "Chapeuzinho", e diversos elementos apresentados no enredo ilustram a cor selecionada para a menina: a Azul possuía olhos azuis, levava uma torta de amoras na cesta e foi pelo caminho de flores azuis; a Cor de abóbora levava na cesta uma torta de abóbora e foi pelo caminho sugerido pelo lobo, onde encontraria diversas árvores frutíferas; a Verde, uma torta de limão e era interessada em dinheiro; a Branco era detentora de olhos e cabelos claros e levava suspiros; a Lilás levava revistas de fofoca e colheu lilases pelo caminho; e a Preta possuía olhos e cabelos pretos e levava jabuticabas.

A máxima "Era uma vez..." inicia todas as narrativas e cada versão possui uma música cantarolada por Chapeuzinho quando está a caminho da casa de sua avó, paródia da táo marcante "Pela estrada a fora eu vou bem sozinha...", produzida por Braguinha ${ }^{3}$, como podemos observar no trecho de uma das histórias contidas na obra: "Pela estrada afora/ Eu vou tão sozinha/ Tão desprotegida/ Ai de mim, tadinha”.

Figura 2: Início da narrativa "Chapeuzinho Azul"

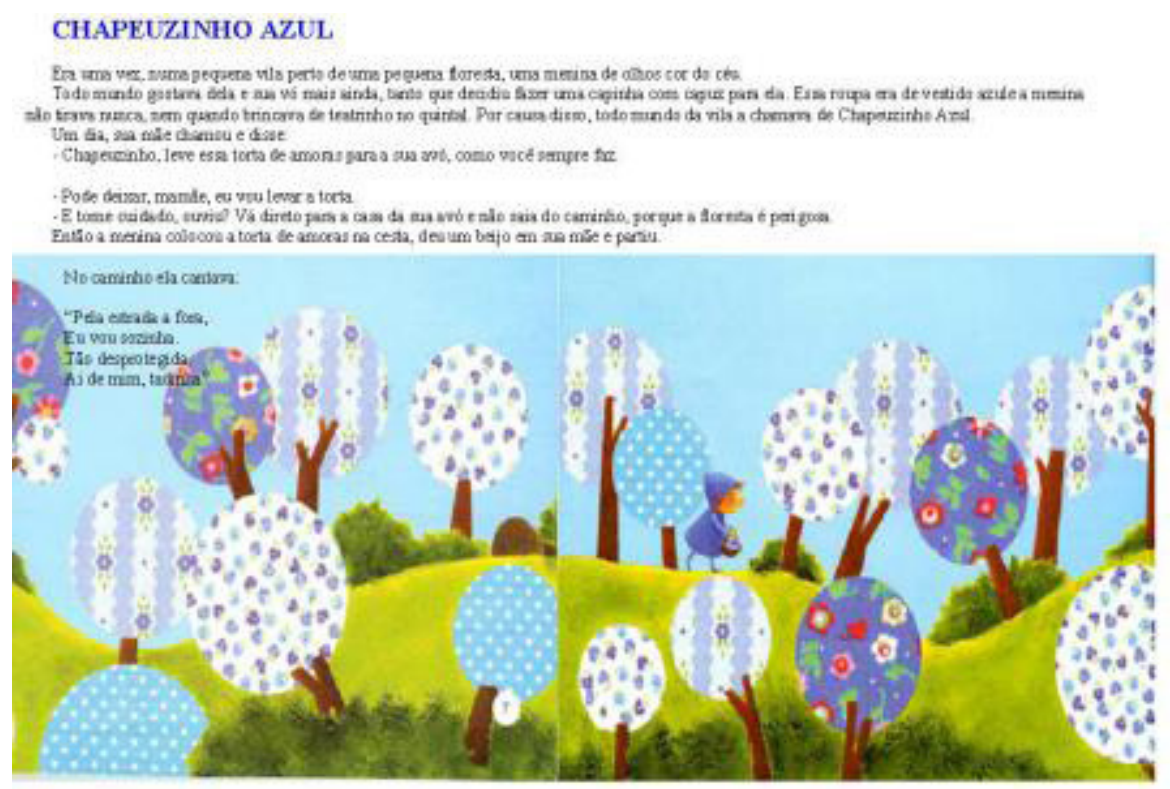

Algo que também chama a atenção nos contos é a ilustração das narrativas produzida por Marília Pirillo, como pode ser observado na Figura 2. A floresta por onde Chapeuzinho passa é constituída de árvores cujas copas apresentam-se no tom da cor do capuz da personagem, assemelhando a retalhos de tecidos de estamparias diversas, mas seguindo a mesma palheta de cores.

Todos esses detalhes elencados chamam a atenção do leitor, despertam a curiosidade e provocam uma série de questionamentos e hipóteses. Depois de ler a primeira narrativa, há uma quebra de expectativa do leitor e este passa a tentar imaginar o que mais pode acontecer com essa menina.

\section{“Chapéus Coloridos" em escolas de Arraias - TO}

Para desenvolver ações dos projetos de extensão "Rodas de leitura: um caminho para formar leitores" e "Contar histórias: um trabalho de sala de aula", entramos em 3 Música Pela estrada, produzida nas décadas de 1950/60 por Braguinha (Coleção Disquinho). 
contato com duas escolas do município de Arraias: Centro Municipal de Educaçáo Básica professora Lívia Lorene Bueno Maia e Cooperativa Educacional de Pais de Arraias (CEPAR). As instituiçóes prontamente aceitaram nossa presença semanalmente e cederam horários em diversas turmas para realizarmos atividades de contação de histórias e rodas de leitura. O intuito era ilustrar aos professores como poderiam desenvolver essas açóes dentro de seu planejamento.

De acordo com a organização feita com as instituiçóes, em uma visita semanal, desenvolveríamos ações de contação de histórias e, em alguns momentos, as rodas de leitura com os alunos. Para a contaçáo de histórias, havia um preparo prévio para a apresentação da obra escolhida, fazendo-se uso de diversos recursos (fantoches, vestimentas, leituras dramáticas etc.). Nas açóes das rodas de leituras, levávamos um quantitativo de obras previamente selecionadas para que fossem escolhidas pelos alunos para lerem em casa durante o intervalo de tempo até o encontro seguinte (uma semana), quando compartilhariam com os demais.

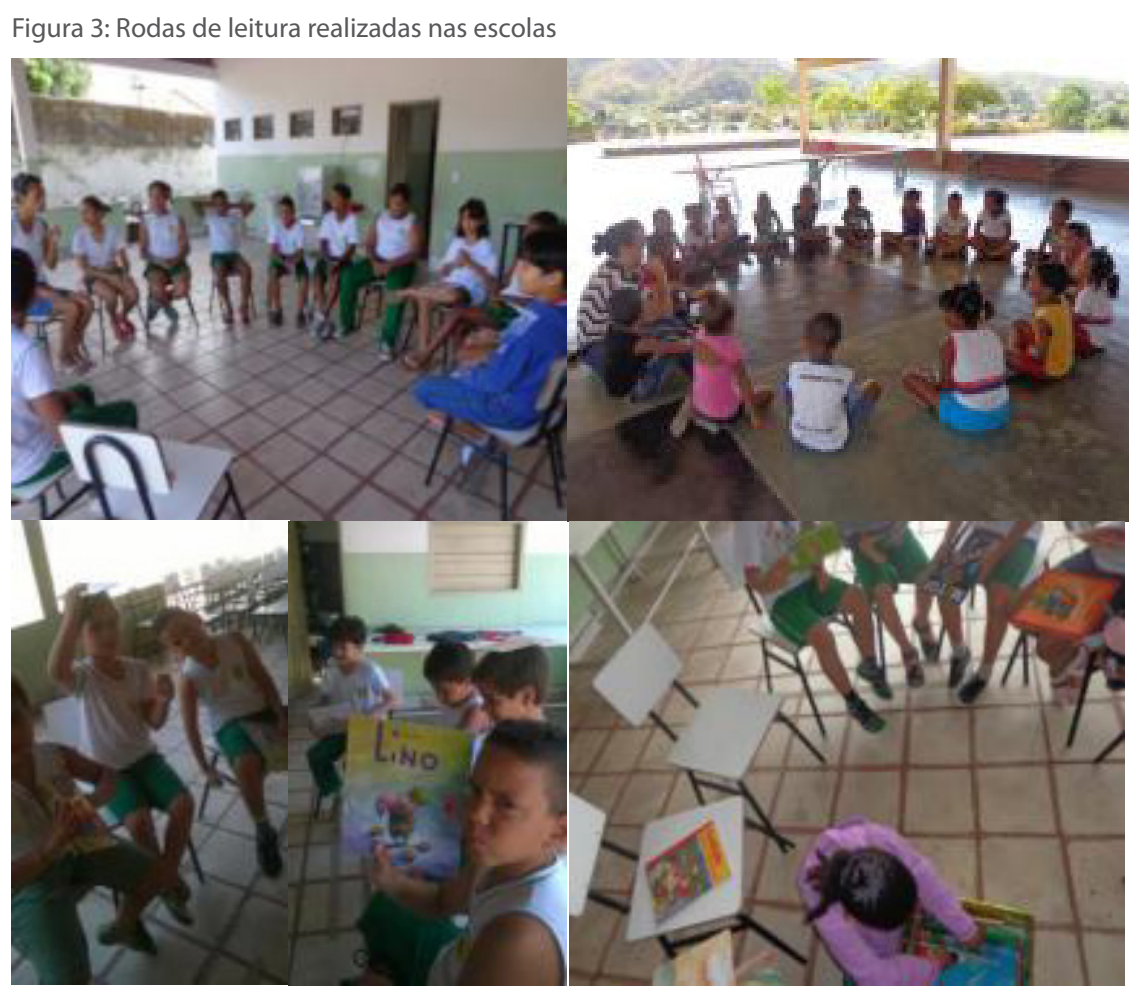

Nessas ações semanais, uma atividade em especial chamou atenção e despertou o interesse de ampliaçáo do anteriormente planejado. Ao trabalhar na CEPAR com a leitura dramática do primeiro conto da obra "Chapeuzinhos Coloridos", de José Roberto Torero e Marcus Aurelius Pimenta, intitulado "Chapeuzinho Azul", houve um processo de encantamento, tanto por parte dos alunos quanto da professora regente do quarto ano.

A recepçáa do texto ultrapassou as expectativas e houve uma interaçáo muito intensa entre extensionista, professores e alunos. Um diálogo muito profícuo se estabeleceu e discussóes se alongaram diante da quebra de expectativa do final da narrativa: "Como assim, o lobo foi assado?", questionava um; "Cada um dá o final que quer para sua história", tentou justificar outro; "eu faria diferente", pontuou um terceiro; "pensei que a Chapeuzinho e Vovozinha eram boas", reclamou outra aluna; "que massa essa história!", disse, empolgado, outro. 
Nesse momento, apresentamos aos alunos alguns dados da obra "Chapeuzinho Vermelho", desde seu primeiro registro da oralidade, feito por Perrault, apontando as diferenças existentes entre essa reescrita da obra e a coletada da oralidade pelos dos Irmáos Grimm, e comentamos sobre as inúmeras versóes que já foram feitas, bem como sobre a liberdade literária que um autor possui ao (re)escrever um texto.

Como atividade do projeto, a professora regente de sala ficou responsável por trabalhar/compartilhar com os alunos os demais contos da obra, um por dia, até o novo encontro com os alunos, na semana seguinte. No entanto, a professora nos telefonou três dias depois, mencionando que o que havia planejado foi, de certa forma, alterado pelos alunos: eles náo conseguiram aguardar o compartilhamento feito pela professora, começaram a fazer pesquisas na internet para ler as demais histórias e eles mesmos compartilharam entre si. Ainda, começou outra troca de informaçóes dentro da própria escola sobre a obra, de aluno para aluno, de professor para professor.

Nessa inquietude curiosa, os próprios alunos da turma, juntamente com a professora, tiveram a ideia de repassar as histórias para as demais turmas e começaram se preparar para isso. Cada dupla de alunos ficou responsável por um conto; criaram cenários com orientação da professora da turma, improvisaram sua caracterizaçáo juntamente com seus pais e, depois de um tempo de preparaçáo, juntaram os alunos das demais turmas no pátio da escola para contar as "suas histórias".

Figura 4: Alunos da CEPAR se preparando para contar histórias

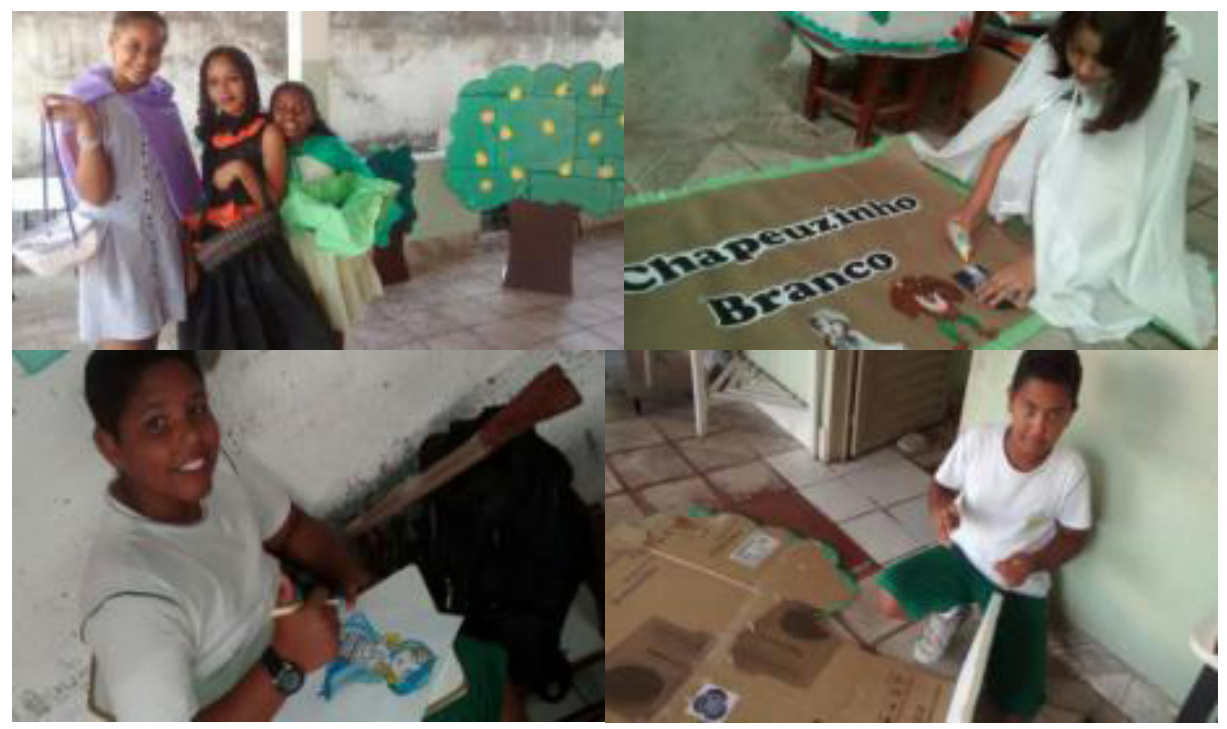

A atividade deu tão certo que foi levada para outra escola parceira. Dessa forma, os pequenos leitores da CEPAR passaram a ser contadores de histórias em sua própria instituição e também no CMEB Prof. Lívia Bueno Maia. Nas imagens a seguir, podemos observar alguns desses momentos. 
Figura 5: Chapeuzinhos e outros personagens contando suas histórias

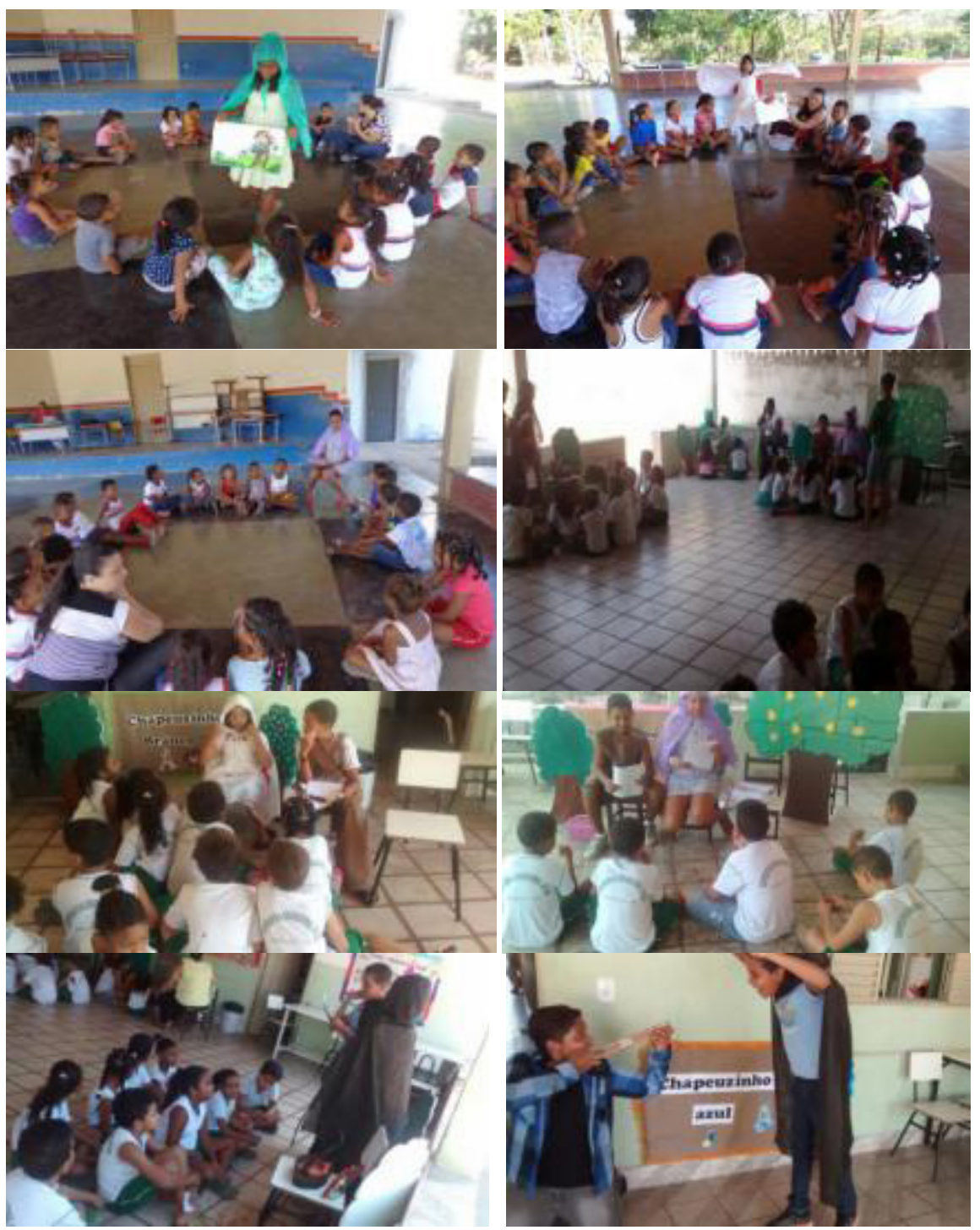

A experiência foi enriquecedora e ultrapassou as expectativas, pois além de exemplificar aos professores das referidas escolas algumas entre as tantas formas possíveis de trabalho com o texto literário, houve uma participação ativa e formação de alunos "leitores-contadores mirins".

\section{Algumas consideraçóes}

O curso de Pedagogia visa à formaçáo de profissionais para as primeiras fases da Educação Básica (Educação Infantil e Ensino Fundamental I), que devem estar atentos às mudanças do mundo contemporâneo e possuir um conhecimento acerca dos processos de ensino e aprendizagem, principalmente no que concerne ao domínio dos conteúdos e dos processos e metodologias de ensino.

O professor das séries/anos iniciais da Educação Básica é, muitas vezes, o único responsável pela formação dos leitores do amanhã e esses leitores mirins têm o mundo da leitura desvelado pelo professor, através da contaçáo de histórias e da oportunização da leitura e de seu compartilhamento em sala. 
Preparar os professores e/ou futuros professores para essas açóes de contaçáo e de rodas é crucial para seu bom desempenho em sala de aula. Assim, poder ofertar curso na área com o apoio e incentivo do PRODOCÊNCIA faz com que cumpramos o novo papel de cursos de formação para a educação. Dessa forma, o PRODOCÊNCIA é uma das ferramentas em defesa do ensino público de qualidade.

Infelizmente, se não houver uma valorização da carreira docente, ela continuará não estando nos objetivos de muitos jovens e a realidade do seu perfil de leitura pode permanecer semelhante ao encontrado atualmente. Diante dessa realidade náo muito animadora, a universidade ainda pode tentar agir na alteração desse perfil, criando estratégias para a ampliação do repertório literário daqueles poucos que querem ser professores e mudar a situação da leitura no país.

Nesse sentido, as rodas ou círculos (os nomes e as descriçóes são menos importantes que seu objetivo central) e a ação de contação de histórias se tornam um espaço de formação para a leitura, tanto como leitor quanto como mediador.

E como fazer isso? Foi o que tentamos mostrar aqui. $\mathrm{O}$ que sugerimos é que a Universidade, via suas pesquisas, atividades extensionistas, bem como as atividades integrantes e complementares dos cursos, e em parcerias com as disciplinas da matriz curricular, estruture pesquisas diagnósticas e cursos de formação para o letramento literário dos universitários.

O que não se deve é ficar colocando a culpa dos outros pontos desse círculo sem assumir seu papel e propor alternativas para o rompimento desse processo ou para a inversão da "não" para a formação de leitores.

\section{Referências}

ABRAMOVICH, Fanny. Literatura infantil: gostosuras e bobices. São Paulo: Scipione, 1988.

AGUIAR, Vera Teixeira de; BORDINI, Maria da Glória. Literatura: a formação do leitor alternativas metodológicas. Porto Alegre: Mercado Aberto, 1988.

BAMBERGER, Richard. Como incentivar o hábito da leitura. 7. ed. São Paulo: Ática/ UNESCO, 2004.

BARCELLOS, Maria Carolina; FEITOSA, Larissa Dias. Suzana Vargas e as rodas de leitura: a literatura em foco. 2013. Disponível em: http://midia.unit.br/enfope/2013/GT7/SUZANA_ VARGAS_RODAS_LEITURA_LITERATURA_FOCO.pdf. Acesso em: 10 out. 2015.

BETTELHEIM, Bruno. A psicanálise dos contos de fada. Rio de Janeiro: Paz e Terra: 1980.

BUARQUE, Chico. Chapeuzinho Amarelo. Rio de Janeiro: José Olympio, 2012.

BUSATTO, Cléo. Contar e encantar. Petrópolis: Vozes, 2003.

COELHO, Nely Novaes. A literatura infantil. 3. ed. São Paulo: Quíron, 1997.

CANDIDO, Antonio. A literatura e a formação do homem. Ciência e Cultura, v.24, n.9, p. 803-809, set. 1979. 
COSSON, Rildo. Círculos de Leitura e Letramento literário. São Paulo: Contexto, 2014.

. Letramento literário: teoria e prática. São Paulo: Contexto, 2006.

DANIELS, Harvey. Literature circles. Voice and choice in Books Clubs and Reading Groups. 2. ed. Portland Maine: Stenhouse Publishers, 2002.

DARNTON, Robert. 0 grande massacre de gatos: e outros episódios da história cultural francesa. Rio de Janeiro: Graal, 1996.

DONATTO, Miriam Edite Canfield. A humanização da infância: uma contribuição da literatura infantil. Monografia (Especialização) - Universidade Federal de Santa Maria, Santa Maria, 2005. Disponível em: <http://repositorio.ufsm.br:8080/xmlui/handle/1/1569>. Acesso em: 14 out. 2016.

FREIRE, Paulo. A importância do ato de ler: em três artigos que se completam. São Paulo: Cortez/Autores Associados, 1992.

MARTINS, Maria Helena. O que é leitura. São Paulo: Brasiliense, 1985.

GERALDI, João Wanderley. Leitura e mediação. In: BARBOSA, Juliana Bertucci; BARBOSA, Marinalva Vieira (Orgs.). Leitura e mediação: reflexões sobre a formação do professor. Campinas, SP: Mercado de Letras, 2013. p. 25-48.

MACHADO, Ana Maria. Como e por que ler os clássicos universais desde cedo. Rio de Janeiro: Objetiva, 2002.

MACHADO, Regina. Acordais: fundamentos teórico-poéticos da arte de contar histórias. São Paulo: Editora DCL.

MELLON, Nancy. A arte de contar histórias. Tradução de Amanda Orlando e Aulyde Soares Rodrigues. Rio de Janeiro: Rocco, 2009.

PRATA, Mário. Chapeuzinho Vermelho de raiva. São Paulo: Globo, 1970.

ROSA, João Guimarães. Fita-verde no cabelo: nova velha história. Rio de Janeiro: Nova Fronteira, 1992.

SANTOS, Fabiano dos; RÖSING, Tânia Mariza Kuchenbecker. Mediação de Leitura discussões e alternativas para a formação de leitores. São Paulo: Global, 2009.

SILVA, Ezequiel Theodoro da. O professor leitor. In: SANTOS, Fabiano dos; MARQUES NETO, José Castilho; RÖSING, Tânia Mariza Kuchenbecker (Orgs.). Mediação de Leitura discussões e alternativas para a formação de leitores. São Paulo: Global, 2009. p. 23-26.

TEHRANI, Jamshid Jamie. The Phylogeny of Little Red Riding Hood. PLOS ONE, v.8, n.11, 2013. Disponível em: <http://journals.plos.org/plosone/article?id=10.1371/journal. pone.0078871>. Acesso em: 10 out. 2016.

TORERO, José Roberto; PIMENTA, Marcus Aurelius. Chapeuzinhos Coloridos. Ilustrações de Marilia Pirillo. Rio de Janeiro: Objetiva, 2010. 
VARGAS, Suzana. Rodas de Leitura: o que são, de onde vieram, para onde vão? In: Leitura: teoria \& prática, n. 29. Porto Alegre: Mercado Aberto; Campinas: ALB, 1997.

ZILBERMAN, Regina. A leitura na escola. In: . (Org.). Leitura em crise na escola: as alternativas do professor. 9. ed. Porto Alegre: Mercado Aberto, 1988. p. 9-22. 